\title{
Transient visual field impairment after cold provocation in glaucoma patients with Flammer syndrome
}

\author{
Barbara Terelak-Borys ${ }^{\mathrm{a}, *}$, Iwona Grabska-Liberek ${ }^{\mathrm{a}}$, Andreas Schoetzau ${ }^{\mathrm{b}}$ and Katarzyna Konieczka ${ }^{\mathrm{b}}$ \\ ${ }^{a}$ Department of Ophthalmology, Centre of Postgraduate Medical Education, Warsaw, Poland \\ ${ }^{\mathrm{b}}$ Department of Ophthalmology, University of Basel, Basel, Switzerland
}

\begin{abstract}
.
Background: It is still debatable whether visual field defects in glaucoma have a reversible component and to what extent a temporary loss can be provoked.

Objective: To investigate the response of the visual function to a cold provocation in glaucoma patients, particularly to test whether subjects with Flammer syndrome (FS) behaved differently from subjects without FS.

Methods: Ten (10) primary open-angle glaucoma (POAG) patients with FS, 7 POAG patients without FS, and 11 healthy controls were tested with program G2 on the Octopus 101 perimeter before and after putting one hand in cold water $\left(4^{\circ} \mathrm{C}\right)$ for $2 \mathrm{~min}$. The mean sensitivity (MS) of each visual field was included in the statistical analysis.

Results: In glaucoma patients with FS, the mean MS significantly decreased after cold provocation (delta MS $=-0.91 \mathrm{~dB}$, $\mathrm{CI}=-1.43$ to $-0.39, p=0.0014$ ). In contrast, the mean MS in glaucoma patients without FS did not change significantly (delta $\mathrm{MS}=0.17 \mathrm{~dB}, \mathrm{CI}=-0.43$ to $0.78, p=0.56$ ). Likewise, the mean MS did not change significantly in the healthy controls (delta $\mathrm{MS}=0.23 \mathrm{~dB}, \mathrm{CI}=-0.27$ to $0.72, p=0.36$ ).

Conclusions: Cold provocation induced a transient visual field deterioration in the glaucoma patients with FS but not in the glaucoma patients without FS or in the healthy controls. We assume this effect to be the result of a transient reduction of ocular blood flow.
\end{abstract}

Keywords: Primary open angle glaucoma, Flammer syndrome, visual field, cold provocation, transient visual field impairment, ocular blood flow

\section{Introduction}

Reversible changes of visual function after cooling one hand have been reported in the literature (Bouvier et al., 1995; Guthauser et al., 1988). In the present study, we aimed to compare this response between glaucoma patients with Flammer syndrome and glaucoma patients without Flammer syndrome.

\footnotetext{
${ }^{*}$ Corresponding author: Barbara Terelak-Borys, Department of Ophthalmology, Centre of Postgraduate Medical Education, Czerniakowska str. 231, 01-416 Warsaw, Poland. Tel.: +48 225841 185; E-mail: bterelak@message.pl.
}

\subsection{Flammer syndrome}

The term Flammer syndrome (FS) (Flammer \& Konieczka, 2017; Flammer et al., 2013; Flammer, Konieczka, \& Flammer, 2013; Konieczka et al., 2014) refers to a phenotype characterized by the presence of primary vascular dysregulation together with a cluster of additional symptoms and signs. It refers to a predisposition to react differently (most often more sensitively) to a number of stimuli, such as coldness (Saner et al., 1987), physical or emotional stress, or high altitude. FS is related to some eye diseases, such as glaucoma, especially normal tension 
glaucoma (NTG) (Flammer et al., 2002; Konieczka et al., 2017; Konieczka \& Erb, 2017; Konieczka et al., 2014), retinitis pigmentosa (Konieczka et al., 2012; Konieczka et al., 2016; Todorova et al., 2015), Leber's hereditary optic neuropathy (Flammer et al., 2013; Konieczka \& Erb, 2017), and optic nerve compartment syndrome (Flammer et al., 2013; Konieczka et al., 2016). FS is also a risk factor for vascular occlusions (Flammer et al., 2013), such as retinal vein occlusions (Flammer \& Konieczka, 2015; Fraenkl et al., 2010), cilioretinal artery occlusions (Konieczka et al., 2015), choroidal infarctions (Terelak-Borys et al., 2017), anterior ischemic optic neuropathies, and Susac syndrome (Flammer et al., 2001). FS is also more often present in patients with multiple sclerosis (Flammer et al., 2013; Konieczka et al., 2016), and it is a risk factor for perioperative visual loss (Bojinova et al., 2016; Bojinova, Konieczka, \& Todorova, 2016) and most likely also for breast cancer and metastatic disease (Bubnov et. al., 2017; Zubor et al., 2017). For more details, we refer to the recently published reviews (Flammer et al., 2013; Flammer, Konieczka, \& Flammer, 2013; Konieczka \& Erb, 2017; Konieczka et al., 2014).

Subjects with FS also have a disturbed regulation of ocular blood flow (OBF) (Gherghel et al., 1999). As a consequence, fluctuation of the intraocular pressure (IOP) and/or the blood pressure results in the fluctuation of the OBF and, therefore, an unstable oxygen supply, which in turn increases oxidative stress. Over the long term, this contributes to the development and progression of glaucomatous optic neuropathy (GON) even in the absence of an increase in the IOP (Flammer et al., 1999; Flammer \& Mozaffarieh, 2008; Flammer et al., 2002; Konieczka et al., 2017). Indeed, the relationship between normal tension glaucoma (NTG) and FS has been reported (Konieczka et al., 2017). In addition, a short-term reduction in oxygen supply can reversibly reduce visual sensitivity as measured by perimetry, a change that is normally not perceived by patients (Brandl \& Lachenmayr, 1994).

\subsection{Peripheral blood flow $(B F)$ in subjects with FS}

In patients with FS, local cooling causes a prolonged BF cessation in the nailfold capillaries. This prolongation is abolished, or at least mitigated, by nifedipine (Mahler et al., 1989). People with FS have also more often cold hands and/or feet (Flammer et al., 2001; Mozaffarieh et al., 2010) and a significantly prolonged sleep-onset time because sleep-onset time is linked to foot temperature (Pache et al., 2001). In FS subjects, the peripheral BF correlates with the BF in the optic nerve head (Mozaffarieh et al., 2010) because the perfusion pressure is the dominant regulating factor if the autoregulation of the $\mathrm{OBF}$ is disturbed.

\subsection{Ocular blood flow regulation $(O B F)$ in $F S$ subjects}

The regulation of the OBF is necessary for adapting to changing conditions. The regulation compensates for varying perfusion pressures, adapts to retinal activity, and keeps the back of the eye at a constant temperature. If the regulation does not act according to the needs of the tissue, this condition is referred to as vascular dysregulation. In the absence of an underlying disease, it is called primary vascular dysregulation. This condition is the core element of FS. A consequence of the reduced regulation of the OBF in FS subjects (Emre et al., 2004; Gherghel et al., 1999) is an unstable OBF and, therefore, an unstable oxygen supply. This instability induces a repeated mild reperfusion injury (Flammer, 2001), i.e., increased oxidative stress, and this contributes to the pathogenesis of GON, particularly in NTG patients (Flammer \& Mozaffarieh, 2008; Flammer et al., 2002; Konieczka et al., 2014).

Healthy FS subjects have a higher spatial irregularity in the retinal arterioles (Kochkorov et al., 2006) and a faster pulse wave propagation, as demonstrated with the retinal vessel analyzer. During cold provocation, this pulse wave propagation is even faster (Gugleta et al., 2006), indicating a further stiffening of the retinal vessels. FS individuals also have a reduced flow-mediated vasodilatation (Gugleta et al., 2006). The choroidal vessels are also involved in the dysregulation (Hasler et al., 2002). In addition, the optic nerve head BF is significantly correlated with the peripheral finger $\mathrm{BF}$, and this is also an indirect sign of a disturbed autoregulation (Mozaffarieh et al., 2010). Furthermore, the retinal venous pressure is increased in FS subjects (Fang et al., 2014).

The goal of our study was to investigate the influence of cold provocation on visual function. We investigated primary open angle glaucoma (POAG) patients with and without FS and compared these patients to the healthy controls. 


\section{Methods}

\subsection{Study participants}

The subjects were informed about an opportunity to participate in a scientific study. The subject matter and the objective of the study were presented by a physician, and informed consent was received from all of the subjects before admission to the study. The study was conducted in the Department of Ophthalmology, Centre of Postgraduate Medical Education, Warsaw, Poland. It was approved by the Bioethics Committee at the Centre of Postgraduate Medical Education, and it was designed and conducted in accordance with the tenets of the Declaration of Helsinki.

Three following study groups were investigated: 10 POAG patients with FS: FS(+), 7 POAG patients without FS: FS(-), and 11 healthy controls. Of the 17 POAG patients, 13 were females, and 4 were males. Nine (9) of them suffered from high tension glaucoma (HTG), and 8 from normal tension glaucoma (NTG). Of the 11 controls, 8 were females, and 3 were males. The POAG patients were divided into groups, FS(+) and FS(-), based on the typical patient's history (cold hands and/or feet, low blood pressure, low body-mass-index), and the diagnosis was confirmed by spontaneous blood flow cessation in nailfold capillaroscopy. There were 9 females and 1 male in the $\mathrm{FS}(+)$ group, and 4 females and 3 males in the FS(-) group.

The ages of the study participants ranged from 20 to 47 , and there were no statistically significant differences in the mean ages of the 3 study groups.

All of the study participants underwent slit lamp and funduscopic examinations, Goldmann applanation tonometry, computerized refractometry, gonioscopy, and computerized perimetry (standard automatized perimetry - SAP, Octopus 101, program G2).

\subsubsection{Glaucoma patients}

For all of the patients slit lamp examination of anterior segment revealed no pathologies. The fundus examination showed typical glaucomatous excavation (cup-to-disc ratio more than 0.5) of the optic nerve heads (ONHs) bilaterally in all the patients; otherwise, the fundus findings were normal (except one eye of a patient with an antecendent retinal vein occlusion). The IOP did not exceed $22 \mathrm{mmHg}$ (measured repeatedly at different time points). The best corrected visual acuity (BCVA) measured with the distance Snellen charts was 1.0 in all eyes except one, which reached 0.5 because of previous central retinal vein occlusion. Refractive errors were between -4.5 diopters and +1.0 diopters of spherical equivalent. The anterior chamber angle was open upon gonioscopic examination without any features of congenital abnormalities.

The POAG group included 13 patients exhibiting perimetric features typical for GON and 4 patients with preperimetric glaucoma (diagnoses confirmed by signs of structural glaucomatous damage in the HRT and/or GDx examinations). In the visual field (VF) examination, the minimal glaucomatous damage was defined as at least 3 adjacent test points with a deviation equal to or greater than $5 \mathrm{~dB}$, with 1 test point with a deviation greater than $10 \mathrm{~dB}$ or at least 2 test points with a deviation equal to or greater than $10 \mathrm{~dB}$. Glaucomatous VF abnormality had to be present in at least one eye of the patient.

The POAG patients did not suffer from any systemic disease. They had normal blood lipids, and they were non-smokers. They did not take any systemic medications except oral contraceptives (in some females). Some patients were treated with topical anti-glaucoma drugs, while others did not receive any treatment because of previous glaucoma surgery. Some patients remained untreated because of recently diagnosed NTG.

\subsubsection{Controls}

The BCVA was 1.0 on distance Snellen charts in all of the controls, with a refractive error comparable to that of glaucoma patients (myopic refractive error not exceeding -3.0 diopters of spherical equivalent and no hyperoptic refractive error). The IOP did not exceed $21 \mathrm{mmHg}$ in any subject. The slit lamp examination, gonioscopy, and funduscopy revealed normal findings. The ONHs were normal and had a c/d ratio ranging from 0.2 to 0.4 . The VF examinations were normal: 8 eyes showed small borderline scotomas not characteristic for glaucoma.

The controls had no ocular or systemic diseases. They were non-smokers, and they did not take any systemic medications except oral contraceptives (in some females).

\subsection{Experimental procedures}

\subsubsection{Visual field examination}

The VF examinations were conducted using the standard white-on-white static computerized perimetry (SAP), Octopus 101, G2 program. Both eyes 
of each subject were examined and included in the study: 22 in the control group, 20 in the FS(+) group, and 14 in the FS(-) group. The reliability factor (RF) was less than 15 in all of the examined eyes.

\subsubsection{Cold provocation}

Cold provocation was performed after $5 \mathrm{~min}$ of the patient's resting in a sitting position at room temperature by immersing the whole hand in cold $\left(4^{\circ} \mathrm{C}\right)$ water for $2 \mathrm{~min}$. The non-dominant hand was chosen for cold provocation and the dominant hand to press the button on the perimeter.

\subsection{Study plan}

The VF examination was performed two times during the day. It was done first under basal conditions (VF-1); then it was repeated immediately after cold provocation (VF-2). Cold provocation was applied 2-3 hours after the VF testing under basal conditions.

"Eye-1" (right eye) was the eye first examined under basal conditions and the first after cold provocation. "Eye-2" (left eye) was the second eye examined under basal conditions and the second after cold provocation. The time lag from cold provocation to the VF examination was 5 minutes for Eye- 1 and 15-20 minutes for Eye-2.

\subsection{Follow-up VF examination}

Investigating the VF recovery after cold provocation was not a part of our study and was not systematically tested. However, 7 of the glaucoma patients ( 5 with FS and 2 without FS) participating in the study and attending control visits in our department had a VF examination within 6-8 months of completing the study. They were then monitored for 1 to 3 years.

\subsection{Statistical methods}

Changes in the VF mean sensitivity (MS) induced by cold provocation, were evaluated in the 3 study groups. The delta MS was defined as the difference between the mean MS after cold provocation and the baseline (delta MS = MS after cold provocation - MS baseline). Linear mixed-effects models were used to compare the MS changes. These kinds of models are suitable tools for repeated measure data because they take into account correlations of withinsubject measurements. The results are presented as the differences of the mean values from zero and as the differences among the study groups, with corresponding $95 \%$ confidence intervals and $p$-values. Two $p$-values are given in the results. The first $p$-value is after adjusting for the eye side and the second $p$-value $\left(p^{*}\right)$ is after additional adjustment for age and gender.

Additionally, descriptive statistics and boxplots were presented for each study group. A $p$-value $<0.05$ was considered significant. All evaluations were done using the statistical software package $\mathrm{R}$ version 3.3.0 (RCore \& Team, 2016).

\section{Results}

\subsection{VF changes after cold provocation}

In the $\mathrm{FS}(+)$ glaucoma patients, the mean MS decreased significantly after cold provocation when compared with the baseline values (delta $\mathrm{MS}=-0.91 \mathrm{~dB}, \mathrm{CI}=-1.43$ to $-0.39, p=0.0014 /$ $\left.p^{*}=0.0024\right)$. In the FS(-) glaucoma patients, the mean MS did not change significantly after cold provocation (delta $\mathrm{MS}=0.17 \mathrm{~dB}, \mathrm{CI}=-0.43$ to 0.78 , $\left.p=0.56 / p^{*}=0.98\right)$. In addition, in the controls, the mean MS did not change significantly after cold provocation (delta $\mathrm{MS}=0.23 \mathrm{~dB}, \mathrm{CI}=-0.27$ to 0.72 , $\left.p=0.36 / p^{*}=0.60\right)($ Fig. 1).

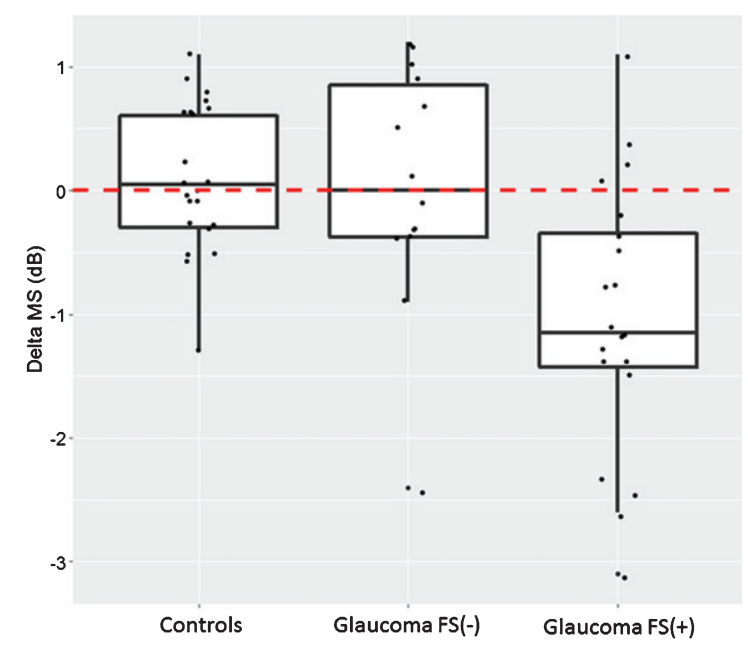

Fig. 1. Perimetric response to cold provocation. $\mathrm{MS}=$ mean sensitivity; delta MS = MS after cold provocation - MS baseline. Results are represented as box-plots in controls, glaucoma patients without Flammer syndrome FS(-), and glaucoma patients with Flammer syndrome FS(+). Each boxplot represents the median and the first and third quartile. A positive delta indicates an improvement; a negative delta, a deterioration. 
The delta MS for the FS(-) glaucoma patients and the controls (delta $=-0.052 \mathrm{~dB}, \mathrm{CI}=-0.79$ to 0.68 , $p=0.89 / p^{*}=0.69$ ) was not significantly different, however there was a significant difference between the delta MS for the FS(+) and the FS(-) glaucoma patients (delta $=1.08 \mathrm{~dB}, \mathrm{CI}=0.33$ to $1.83, p=0.0064$ $\left./ p^{*}=0.034\right)$. The delta MS was also significantly different between the $\mathrm{FS}(+)$ glaucoma patients and the controls (delta $=-1.13 \mathrm{~dB}, \mathrm{CI}=-1.80$ to -0.47 , $\left.p=0.0017 / p^{*}=0.0051\right)$.

The time between cold provocation and the beginning of the perimetric test was 5 minutes for the first eye ("Eye-1") and 15-20 minutes for the second eye ("Eye-2"). The responses in the first and second eyes were not statistically significant different for any of the study groups (results not shown).

An example of VF deterioration after cold provocation is presented in Fig. 2.

\subsection{VF recovery}

Although VF recovery after cold provocation was not a part of this study, 7 of the glaucoma patients (5 with FS and 2 without FS) participating in our study had the first VF repetition for clinical purposes within 6-8 months. In all of these patients, the VF recovered to the pre-experimental MS values. During the 1 to 3-year observation period (after the end of the study), the 7 patients were examined repeatedly. We observed MS fluctuations but no evident VF decline.

\section{Discussion}

This study demonstrates that patients who had both glaucoma and FS responded to cold provocation with VF deterioration, whereas neither the glaucoma patients without FS nor the control subjects showed any VF deterioration. This is in accordance with the results of previous studies (Gasser et al., 1990; Guthauser et al., 1988; Nicolela et al., 2003). It is also in line with the nifedipine-induced improvement of VFs seen in patients with FS (Gasser \& Flammer, 1990; Guthauser et al., 1988). The increased vasospastic response to cold is indeed a potential risk factor for GON, especially in NTG patients (Drance et al., 1988; Flammer \& Drance, 1983b; Gasser \& Flammer, 1987; Gasser \& Flammer, 1991; Mahler et al., 1989; O'Brien \& Butt, 1999). Hand cooling of POAG, especially in the NTG patients, reduced the amplitude of blue-on-yellow visual evoked potentials (Horn et al., 2006) and reduced the amplitude of pattern electroretinogram (La Mancusa et al., 2014).

The VF deterioration induced by cooling a hand is most likely the result of the reduction of the OBF. There are many studies supporting the assumption that a transient change of blood or oxygen supply to the eye induces changes in visual function. Carbon dioxide breathing during perimetry can induce a transient improvement of VF (Pillunat et al., 1994) and transient reduction of oxygen saturation transiently reduces the VF (Brandl \& Lachenmayr, 1994). The mechanism, however, by which this local cooling reduces OBF is not known. Several mechanisms could potentially be involved. They include the stimulation of the autonomic nervous system or an increase in the plasma level of catecholamines, endothelin, or other vasoconstrictors. These circulating hormones have a particular effect on the blood vessels in the $\mathrm{ONH}$ because the $\mathrm{ONH}$ lacks a proper blood-brain barrier (Hofman et al., 2001).

But why do the VFs deteriorate only in the glaucoma patients with FS and not in the glaucoma patients without FS or the healthy controls? Although the cause needs to be clarified, the observation fits well with the fact that the blood vessels of the subjects with FS and, in particular, of those with both FS and glaucoma responded differently to a number of stimuli (Konieczka et al., 2014; Saner et al., 1987). These patients have a longer flow cessation in the nail fold capillaries after local cooling (Mahler et al., 1989). They have a greater increase in the plasma level of the endothelin after cooling with a head vest containing coolant fluid (Nicolela et al., 2003), an endothelin sensitivity that is inversely related to blood pressure (Gass et al., 1997), an abnormal endothelin response to postural changes (Kaiser et al., 1995), and an increased vascular response to gas perturbations (Gugleta et al., 2005) or hand-grip stress (Gugleta et al., 2003).

The recovery after the cold-induced VF deterioration was not a part of our study and has not been systematically tested. Nevertheless, some of the glaucoma patients had follow-up VF examinations for clinical purposes, and in all of them, the VF was back to the baseline.

Glaucomatous VF defects have often been considered irreversible. However, a VF improvement in glaucoma patients, particularly in glaucoma patients with FS, can be induced by carbonic anhydrase inhibitors such as acetazolamide taken orally (Flammer \& Drance, 1983a) or, to some extent, dorzolamide applied locally (Bernd, et al., 2001). This 

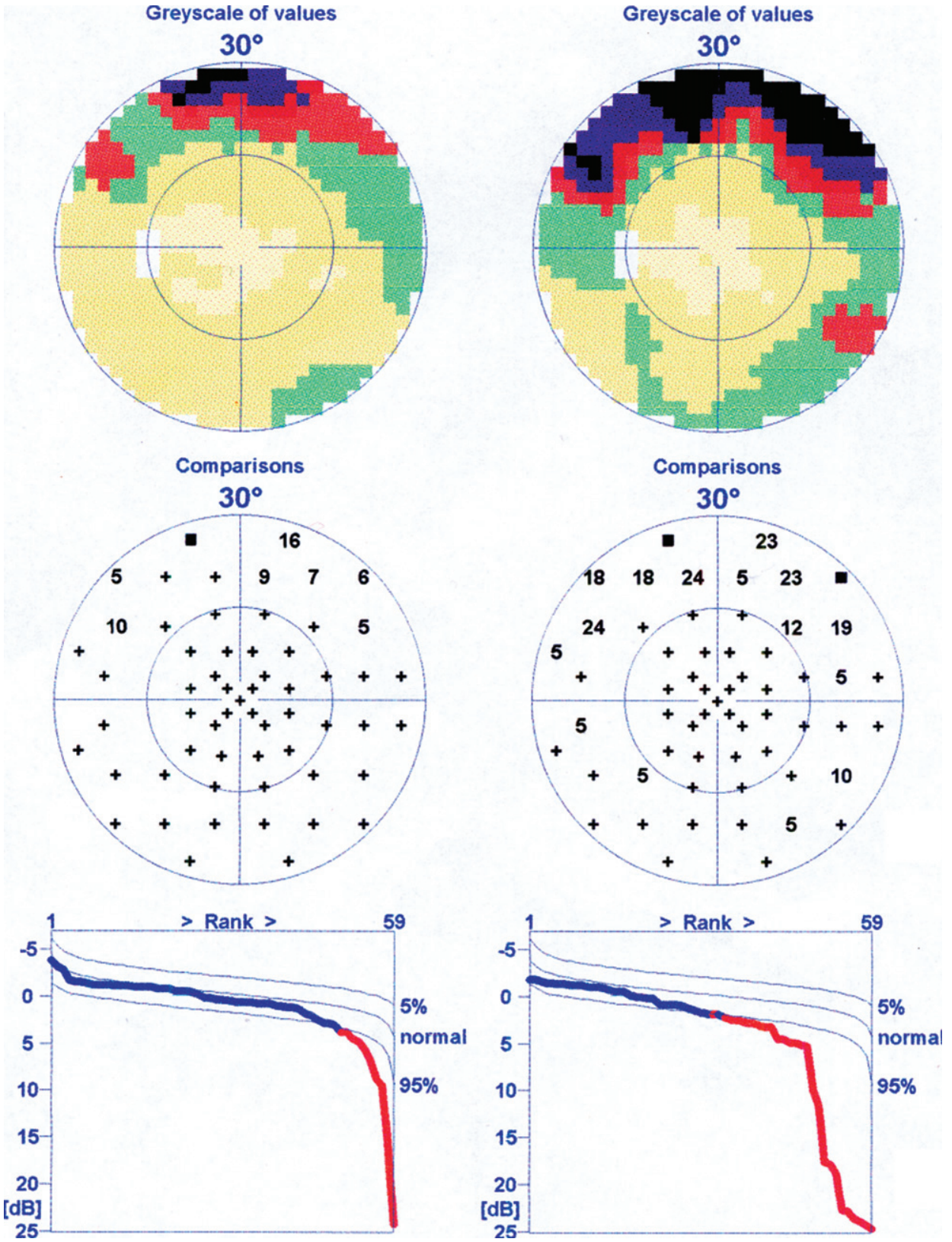

Fig. 2. An example of visual field deterioration after cold provocation in a patient with both normal tension glaucoma and Flammer syndrome. Left: before cold provocation (VF-1). Right: after cold provocation (VF-2).

improvement is not simply the result of the IOP lowering effect, given that other IOP-lowering drugs do not improve the VF and non-IOP lowering treatments, such as breathing carbon dioxide (Pillunat et al., 1994) or taking calcium channel blockers (CCB) also improve the VF (Boehm et al., 2003; Kitazawa et al., 1989; Tomita et al., 1999; Yamamoto et al., 1998). For example, nifedipine has a significant beneficial effect on the VFs of FS patients, both in the short term and the long term (Gasser \& Flammer, 1990). In the POAG patients suffering from a combination of optic nerve compartment syndrome and FS, a treatment with a CCB improved both the optic nerve compartments and the VFs (Konieczka et al., 2016).

A repetitive transorbital alternating current stimulation also improves the VFs of some patients with optic nerve damage, probably by modulating brain 
plasticity (Gall et al., 2016). It has also been reported that the VF in glaucoma patients can be improved by systematic vision stimulation using behavioral, computer-based vision training. Neuroplasticity of the visual cortex or higher cortical areas is the proposed mechanism of action (Gudlin et al., 2008; Sabel $\&$ Gudlin, 2014). At the present time, we do not know whether subjects with FS respond differently and whether this treatment influences circulation.

\section{Conclusions}

Our study demonstrated a transient VF deterioration after peripheral cold provocation in patients with both glaucoma and FS. We assume this effect to be the result of a transient reduction of ocular blood flow.

\section{References}

Bernd, A.S., Pillunat, L.E., Bohm, A.G., Schmidt, K.G., \& Richard, G. (2001). Ocular hemodynamics and visual field in glaucoma treated with dorzolamide. Der Ophthalmologe, 98(5), 451-455.

Boehm, A.G., Breidenbach, K.A., Pillunat, L.E., Bernd, A.S., Mueller, M.F., \& Koeller, A.U. (2003). Visual function and perfusion of the optic nerve head after application of centrally acting calcium-channel blockers. Graefe's Archive for Clinical and Experimental Ophthalmology, 241(1), 34-38.

Bojinova, R.I., Konieczka, K., Meyer, P., \& Todorova, M.G. (2016). The trilateral link between anaesthesia, perioperative visual loss and Flammer syndrome. BioMed Central Anesthesiology, 16, 10 .

Bojinova, R.I., Konieczka, K., \& Todorova, M.G. (2016). Unilateral Loss of Vision after Spinal Surgery in a Patient with Flammer Syndrome. Klinische Monatsblätter für Augenheilkunde, 233(4), 429-431.

Bouvier, P., Berrod, J.P., Garniche, J., Schmidt, C., \& Raspiller, A. (1995). Ocular vasospasm in cold provocation test and primary vascular acrosyndrome. Journal Francais D'Ophtalmologie, 18(2), 151-153.

Brandl, H., \& Lachenmayr, B. (1994). Dependence of the sensitivity of the central visual field on hemoglobin-oxygen saturation. Der Ophthalmologe, 91(2), 151-155.

Bubnov, R., Polivka, J., Jr., Zubor, P., Konieczka, K., \& Golubnitschaja, O. (2017). "Pre-metastatic niches" in breast cancer: Are they created by or prior to the tumour onset? "Flammer Syndrome" relevance to address the question. EPMA Journal, 8(2), 141-157.

Drance, S.M., Douglas, G.R., Wijsman, K., Schulzer, M., \& Britton, R.J. (1988). Response of blood flow to warm and cold in normal and low-tension glaucoma patients. American Journal of Ophthalmology, 105(1), 35-39.

Emre, M., Orgul, S., Gugleta, K., \& Flammer, J. (2004). Ocular blood flow alteration in glaucoma is related to systemic vascular dysregulation. British Journal of Ophthalmology, 88(5), 662-666.

Fang, L., Baertschi, M., \& Mozaffarieh, M. (2014). The effect of Flammer syndrome on retinal venous pressure. BioMed Central Ophthalmology, 14, 121.

Flammer, J. (2001). Glaucomatous optic neuropathy: A reperfusion injury. Klinische Monatsblätter für Augenheilkunde, 218(5), 290-291.

Flammer, J., \& Drance, S.M. (1983a). Effect of acetazolamide on the differential threshold. Archives of Ophthalmology, 101(9), 1378-1380.

Flammer, J., \& Drance, S.M. (1983b). Reversibility of a glaucomatous visual field defect after acetazolamide therapy. Canadian Journal of Ophthalmology, 18(3), 139-141.

Flammer, J., Haefliger, I.O., Orgul, S., \& Resink, T. (1999). Vascular dysregulation: A principal risk factor for glaucomatous damage? Journal of Glaucoma, 8(3), 212-219.

Flammer, J., Kaiser, H., \& Haufschild, T. (2001). Susac syndrome: A vasospastic disorder? European Journal of Ophthalmology, 11(2), 175-179.

Flammer, J., \& Konieczka, K. (2015). Retinal venous pressure: The role of endothelin. EPMA Journal, 6, 21.

Flammer, J., \& Konieczka, K. (2017). The discovery of the Flammer syndrome: A historical and personal perspective. EPMA Journal, 8(2), 75-97.

Flammer, J., Konieczka, K., Bruno, R.M., Virdis, A., Flammer, A.J., \& Taddei, S. (2013). The eye and the heart. European Heart Journal, 34(17), 1270-1278.

Flammer, J., Konieczka, K., \& Flammer, A.J. (2013). The primary vascular dysregulation syndrome: Implications for eye diseases. EPMA Journal, 4(1), 14.

Flammer, J., \& Mozaffarieh, M. (2008). Autoregulation, a balancing act between supply and demand. Canadian Journal of Ophthalmology, 43(3), 317-321.

Flammer, J., Orgul, S., Costa, V.P., Orzalesi, N., Krieglstein, G.K., Serra, L.M.,... \& Stefansson, E. (2002). The impact of ocular blood flow in glaucoma. Progress in Retinal and Eye Research, 21(4), 359-393.

Flammer, J., Pache, M., \& Resink, T. (2001). Vasospasm, its role in the pathogenesis of diseases with particular reference to the eye. Progress in Retinal and Eye Research, 20(3), 319-349.

Fraenkl, S.A., Mozaffarieh, M., \& Flammer, J. (2010). Retinal vein occlusions: The potential impact of a dysregulation of the retinal veins. EPMA Journal, 1(2), 253-261.

Gall, C., Schmidt, S., Schittkowski, M.P., Antal, A., Ambrus, G.G., Paulus, W.,... \& Sabel, B.A. (2016). Alternating current stimulation for vision restoration after optic nerve damage: A randomized clinical trial. PLoS One, 11(6), e0156134.

Gass, A., Flammer, J., Linder, L., Romerio, S.C., Gasser, P., \& Haefeli, W.E. (1997). Inverse correlation between endothelin1 -induced peripheral microvascular vasoconstriction and blood pressure in glaucoma patients. Graefe's Archive for Clinical and Experimental Ophthalmology, 235(10), 634638.

Gasser, P., \& Flammer, J. (1987). Influence of vasospasm on visual function. Documenta Ophthalmologica, 66(1), 3-18.

Gasser, P., \& Flammer, J. (1990). Short- and long-term effect of nifedipine on the visual field in patients with presumed 
vasospasm. Journal of International Medical Research, 18(4), 334-339.

Gasser, P., \& Flammer, J. (1991). Blood-cell velocity in the nailfold capillaries of patients with normal-tension and high-tension glaucoma. American Journal of Ophthalmology, 111(5), 585588 .

Gasser, P., Flammer, J., Guthauser, U., \& Mahler, F. (1990). Do vasospasms provoke ocular diseases? Angiology, 41(3), 213220.

Gherghel, D., Orgul, S., Dubler, B., Lubeck, P., Gugleta, K., \& Flammer, J. (1999). Is vascular regulation in the central retinal artery altered in persons with vasospasm? Archives of Ophthalmology, 117(10), 1359-1362.

Gudlin, J., Mueller, I., Thanos, S., \& Sabel, B.A. (2008). Computer based vision restoration therapy in glaucoma patients: A small open pilot study. Restorative Neurology and Neuroscience, 26(4-5), 403-412.

Gugleta, K., Kochkorov, A., Katamay, R., Zawinka, C., Flammer, J., \& Orgul, S. (2006). On pulse-wave propagation in the ocular circulation. Investigative Ophthalmology \& Visual Science, 47(9), 4019-4025.

Gugleta, K., Orgul, S., Hasler, P., \& Flammer, J. (2005). Circulatory response to blood gas perturbations in vasospasm. Investigative Ophthalmology \& Visual Science, 46(9), 3288-3294.

Gugleta, K., Orgul, S., Hasler, P.W., Picornell, T., Gherghel, D., \& Flammer, J. (2003). Choroidal vascular reaction to hand-grip stress in subjects with vasospasm and its relevance in glaucoma. Investigative Ophthalmology \& Visual Science, 44(4), 1573-1580.

Gugleta, K., Zawinka, C., Rickenbacher, I., Kochkorov, A., Katamay, R., Flammer, J., \& Orgul, S. (2006). Analysis of retinal vasodilation after flicker light stimulation in relation to vasospastic propensity. Investigative Ophthalmology \& Visual Science, 47(9), 4034-4041.

Guthauser, U., Flammer, J., \& Mahler, F. (1988). The relationship between digital and ocular vasospasm. Graefe's Archive for Clinical and Experimental Ophthalmology, 226(3), 224-226.

Hasler, P.W., Orgul, S., Gugleta, K., Vogten, H., Zhao, X., Gherghel, D., \& Flammer, J. (2002). Vascular dysregulation in the choroid of subjects with acral vasospasm. Archives of Ophthalmology, 120(3), 302-307.

Hofman, P., Hoyng, P., vanderWerf, F., Vrensen, G.F., \& Schlingemann, R.O. (2001). Lack of blood-brain barrier properties in microvessels of the prelaminar optic nerve head. Investigative Ophthalmology \& Visual Science, 42(5), 895-901.

Horn, F.K., Michelson, G., Schnitzler, E., Mardin, C.Y., Korth, M., \& Junemann, A.G. (2006). Visual evoked potentials of the blue-sensitive pathway under cold provocation in normals and glaucomas. Journal of Glaucoma, 15(1), 17-22.

Kaiser, H.J., Flammer, J., Wenk, M., \& Luscher, T. (1995). Endothelin-1 plasma levels in normal-tension glaucoma: Abnormal response to postural changes. Graefe's Archive for Clinical and Experimental Ophthalmology, 233(8), 484-488.

Kitazawa, Y., Shirai, H., \& Go, F.J. (1989). The effect of $\mathrm{Ca} 2(+)$-antagonist on visual field in low-tension glaucoma. Graefe's Archive for Clinical and Experimental Ophthalmology, 227(5), 408-412.

Kochkorov, A., Gugleta, K., Zawinka, C., Katamay, R., Flammer, J., \& Orgul, S. (2006). Short-term retinal vessel diameter variability in relation to the history of cold extremities. Investigative Ophthalmology \& Visual Science, 47(9), 4026-4033.

Konieczka, K., Choi, H.J., Koch, S., Fankhauser, F., Schoetzau, A., \& Kim, D.M. (2017). Relationship between normal tension glaucoma and Flammer syndrome. EPMA Journal, 8(2), 111117.

Konieczka, K., \& Erb, C. (2017). Diseases potentially related to Flammer syndrome. EPMA Journal, 8(4), 327-332.

Konieczka, K., Flammer, A.J., Todorova, M., Meyer, P., \& Flammer, J. (2012). Retinitis pigmentosa and ocular blood flow. EPMA Journal, 3(1), 17.

Konieczka, K., Flammer, J., Sternbuch, J., Binggeli, T., \& Fraenk1, S. (2017). Leber's hereditary optic neuropathy, normal tension glaucoma, and Flammer syndrome: Long term follow-up of a patient. Klinische Monatsblätter für Augenheilkunde, 234(4), 584-587.

Konieczka, K., Frankl, S., Todorova, M.G., \& Henrich, P.B. (2014). Unstable oxygen supply and glaucoma. Klinische Monatsblätter für Augenheilkunde, 231(2), 121-126.

Konieczka, K., Koch, S., Binggeli, T., Schoetzau, A., \& Kesselring, J. (2016). Multiple sclerosis and primary vascular dysregulation (Flammer syndrome). EPMA Journal, 7, 13.

Konieczka, K., Koch, S., Schoetzau, A., \& Todorova, M.G. (2016). Increased prevalence of Flammer syndrome in patients with retinitis pigmentosa. Klinische Monatsblätter für Augenheilkunde, 233(4), 448-452.

Konieczka, K., Ritch, R., Traverso, C.E., Kim, D.M., Kook, M.S., Gallino, A.,... \& Yao, K. (2014). Flammer syndrome. EPMA Journal, 5(1), 11.

Konieczka, K., Todorova, M.G., Bojinova, R.I., Binggeli, T., Chackathayil, T.N., \& Flammer, J. (2016). Unexpected effect of calcium channel blockers on the optic nerve compartment syndrome. Klinische Monatsblätter für Augenheilkunde, 233(4), 387-390.

Konieczka, K., Todorova, M.G., Chackathayil, T.N., \& Henrich, P.B. (2015). Cilioretinal artery occlusion in a young patient with Flammer syndrome and increased retinal venous pressure. Klinische Monatsblätter für Augenheilkunde, 232(4), 576-578.

La Mancusa, A., Horn, F.K., Kremers, J., Huchzermeyer, C., Rudolph, M., \& Junemann, A. (2014). Pattern electroretinograms during the cold pressor test in normals and glaucoma patients. Investigative Ophthalmology \& Visual Science, 55(4), 2173-2179.

Mahler, F., Saner, H., Wurbel, H., \& Flammer, J. (1989). Local cooling test for clinical capillaroscopy in Raynaud's phenomenon, unstable angina, and vasospastic visual disorders. Vasa, 18(3), 201-204.

Mozaffarieh, M., Fontana Gasio, P., Schotzau, A., Orgul, S., Flammer, J., \& Krauchi, K. (2010). Thermal discomfort with cold extremities in relation to age, gender, and body mass index in a random sample of a Swiss urban population. Population Health Metrics, 8, 17.

Mozaffarieh, M., Osusky, R., Schotzau, A., \& Flammer, J. (2010). Relationship between optic nerve head and finger blood flow. European Journal of Ophthalmology, 20(1), 136-141.

Nicolela, M.T., Ferrier, S.N., Morrison, C.A., Archibald, M.L., LeVatte, T.L., Wallace, K.,...\& LeBlanc, R.P. (2003). Effects of cold-induced vasospasm in glaucoma: The role of 
endothelin-1. Investigative Ophthalmology \& Visual Science, 44(6), 2565-2572.

O'Brien, C., \& Butt, Z. (1999). Blood flow velocity in the peripheral circulation of glaucoma patients. Ophthalmologica, 213(3), 150-153.

Pache, M., Krauchi, K., Cajochen, C., Wirz-Justice, A., Dubler, B., Flammer, J., \& Kaiser, H.J. (2001). Cold feet and prolonged sleep-onset latency in vasospastic syndrome. Lancet, 358(9276), 125-126.

Pillunat, L.E., Lang, G.K., \& Harris, A. (1994). The visual response to increased ocular blood flow in normal pressure glaucoma. Survey of Ophthalmology, 38 Suppl, S139-S147.

RCore, \& Team. (2016). R: A language and environment for statistical computing. $R$ Foundation for Statistical Computing, Vienna, Austria. URL https://www.R-project.org/.

Sabel, B.A., \& Gudlin, J. (2014). Vision restoration training for glaucoma: A randomized clinical trial. JAMA Ophthalmology, 132(4), 381-389.

Saner, H., Wurbel, H., Mahler, F., Flammer, J., \& Gasser, P. (1987). Microvasculatory evaluation of vasospastic syndromes. Advances in Experimental Medicine and Biology, $220,215-218$
Terelak-Borys, B., Grabska-Liberek, I., Piekarniak-Wozniak, A., \& Konieczka, K. (2017). Choroidal infarction in a glaucoma patient with Flammer syndrome: A case report with a long term follow-up. BioMed Central Ophthalmology, 17(1), 23.

Todorova, M.G., Josifova, T., \& Konieczka, K. (2015). Endothelin1 plasma levels in patients with both retinitis pigmentosa and Flammer syndrome. Klinische Monatsblätter für Augenheilkunde, 232(4), 514-518.

Tomita, G., Niwa, Y., Shinohara, H., Hayashi, N., Yamamoto, T., \& Kitazawa, Y. (1999). Changes in optic nerve head blood flow and retrobular hemodynamics following calcium-channel blocker treatment of normal-tension glaucoma. International Ophthalmology, 23(1), 3-10.

Yamamoto, T., Niwa, Y., Kawakami, H., \& Kitazawa, Y. (1998). The effect of nilvadipine, a calcium-channel blocker, on the hemodynamics of retrobulbar vessels in normal-tension glaucoma. Journal of Glaucoma, 7(5), 301-305.

Zubor, P., Gondova, A., Polivka, J., Jr., Kasajova, P., Konieczka, K., Danko, J., \& Golubnitschaja, O. (2017). Breast cancer and Flammer syndrome: Any symptoms in common for prediction, prevention and personalised medical approach? EPMA Journal, 8(2), 129-140. 